J. Dairy Sci. 97:1305-1312

http://dx.doi.org/10.3168/jds.2013-7643

(C) American Dairy Science Association ${ }^{\circledR}, 2014$.

\title{
Enterotoxin-producing Staphylococcus aureus genotype $B$ as a major contaminant in Swiss raw milk cheese
}

\author{
J. Hummerjohann, ${ }^{* 1}$ J. Naskova, ${ }^{*}$ A. Baumgartner, $\dagger$ and H. U. Graber ${ }^{*}$ \\ ${ }^{*}$ Agroscope Liebefeld-Posieux Research Station ALP-Haras, Schwarzenburgstrasse 161, 3003 Berne, Switzerland \\ †Swiss Federal Office of Public Health, Schwarzenburgstrasse 165, 3003 Berne, Switzerland
}

\begin{abstract}
The objective of this study was to characterize Staphylococcus aureus isolates from Swiss raw milk cheeses that had been found to be contaminated with coagulasepositive staphylococci and to estimate the frequency of the various genotypes, in particular the mastitis-associated Staph. aureus genotype B (GTB). The isolates were also tested for staphylococcal enterotoxin (SE) genes and other virulence factors. From 623 coagulasepositive staphylococci isolated from 78 contaminated raw milk cheeses, 609 were found to be Staphylococcus aureus. Genotyping of all Staph. aureus isolates was performed by PCR amplification of the 16S-23S rRNA intergenic spacer region, as this method was used previously to differentiate between mastitis subtypes associated with their clinical outcome. In total, 20 different genotypes were obtained and the 5 most frequently occurring genotypes were distributed in $6.4 \%$ or more of the samples. The enterotoxin-producing Staph. aureus GTB, known for its high contagiousness and increased pathogenicity in Swiss mastitis herds, was found to be the most abundant subtype at the sample level (71.8\%) as well as among the isolates (62.0\%). A subset of 107 isolates of the different genotypes were analyzed for the presence of SE genes and revealed 9 different SE gene patterns, with sed being most frequently detected and $26 \%$ being PCR-negative for SE genes. Almost all isolates of the major contaminant GTB contained the SE gene pattern sed, sej, ser, with half of them additionally carrying sea. Production of SE in vitro was consistent with the SE genes detected in most of the cases; however, some isolated GTB did not produce SEA. Staphylococcus aureus Protein A (spa) typing revealed 30 different subtypes and most GTB isolates belonged to the bovine spa type t2953; GTB/t2953 was linked among other subtypes to SE production in cheese and staphylococcal intoxication cases. Furthermore, 1 of the 623 isolates was a methicillin-resistant Staph. aureus,
\end{abstract}

Received October 25, 2013.

Accepted November 24, 2013.

${ }^{1}$ Corresponding author: joerg.hummerjohann@agroscope.admin.ch which was an seh-carrying Staph. aureus spa type t127 (non-GTB). We conclude that control and reduction of enterotoxigenic Staph. aureus GTB in dairy herds in Switzerland will not only prevent economic losses at the farm level but also improve the safety of raw milk cheeses; distribution of methicillin-resistant Staph. aureus via raw milk cheese is of less concern.

Key words: Staphylococcus aureus, subtyping, mastitis, raw milk cheese

\section{INTRODUCTION}

Staphylococcus aureus is one of the most important causes of chronic, clinical, or subclinical bovine mastitis worldwide and is associated with great economic losses in dairy. This species is also well known for its causative role in food poisoning outbreaks. The types of food associated with staphylococcal food poisoning (SFP) vary widely between countries and include milk, cream, cheeses, ham, sausages, salads, mushrooms, and cooked meals (Hennekinne et al., 2012). The importance of milk and milk products in SFP has been reviewed by De Buyser et al. (2001). In Switzerland, 7 of the reported 11 SFP outbreaks from 1996 to 2006 were linked to consumption of cheese (Baumgartner, 2008).

Enterotoxin A (SEA) and enterotoxin D (SED) are the most common staphylococcal enterotoxins (SE) observed in association with SFP (Balaban and Rasooly, 2000). These SE, together with the enterotoxins B (SEB), C (SEC), E (SEE) and the toxic shock syndrome toxin-1 (TST), have been well known for many years, whereas the toxins SEG, SEH, SEI, SER, SES, and SET and the enterotoxin-like (SEI) proteins SElJ to SElQ and SElU to SEIV have only been reported more recently, as reviewed by Hennekinne et al. (2012). All SE and SEl proteins have superantigenic properties, resulting in nonspecific polyclonal T-cell expansion followed by massive release of cytokines, which may induce toxic shock. In addition, SEA, SEB, SEC, SED, SEE, SEG, SEH, SEI, SER, SES, and SET are all capable of inducing emesis. However, commercial detection kits are available only for the "classical" enterotoxins SEA to SEE. The control of SE production 
is complex and involves various genetic loci, including the quorum-sensing accessory gene regulator (agr) operon. This fact may explain the observation that a relatively dense growth of Staph. aureus (approximately $10^{5} \mathrm{cfu} / \mathrm{g}$ ) is necessary for SFP. The occurrence of different patterns of SE gene expression and SE protein production depend on the SE type and diverse other factors, including whether the growth of Staph. aureus takes place in an artificial laboratory medium or a food matrix such as raw milk or cheese (Derzelle et al., 2009; Duquenne et al., 2010; Pexara et al., 2012).

A recent study from Switzerland (Fournier et al., 2008) isolated Staph. aureus from bovine IMI and found that the species is a heterogeneous group in that country. A total of 17 genotypes were detected by ribosomal spacer PCR from 101 epidemiologically independent isolates. Two of the genotypes, B (GTB) and C (GTC), predominated, accounting for $80.2 \%$ of the isolates, whereas the other genotypes $(\mathbf{O G})$ were rarely detected ( 1 to $4 \%$ of the isolates). The different genotypes were highly associated with their virulence gene patterns. In particular, GTB was characterized by the presence of the sea, sed, and sej, a long x-region of spa, and a GTB-typical SNP in the leukocidin E (lukE) gene. In contrast, GTC was positive for sec, seg, sei, and $t s t$, a short $\mathrm{x}$-region of spa, and no SNP in the $l u k E$ gene. The $\mathrm{OG}$ were heterogeneous in their virulence gene patterns. Likewise, Fournier et al. (2008) found differences in the prevalence of IMI among genotypes. If GTB was isolated, the median cow prevalence in a herd was $47.2 \%$, whereas for GTC and OG the median prevalence was $7.1 \%(P<0.001)$ and $6.3 \%(P<0.001)$, respectively. Thus, Staph. aureus GTB is involved in a herd problem (many cows infected), whereas GTC and $\mathrm{OG}$ are associated with individual cow disease (Fournier et al., 2008; Graber et al., 2009).

Raw milk is commonly used for the production of Swiss cheese because the milk enzymes add to the desired taste of the cheese. As a consequence, the bacterial flora present in the milk delivered by the farmers is crucial for cheese quality and safety. This flora is greatly influenced by the milking hygiene of the farmer and the bacterial udder health of a herd. Particularly in the case of Staph. aureus GTB, which causes herd problems of mastitis, the delivered milk is expected to be enriched by this subtype, so that increased amounts of Staph. aureus may also be present in the dairy products. In addition, Staph. aureus present in these products may also originate from other sources, including humans or contaminated equipment (Jørgensen et al., 2005; Kérouanton et al., 2007; Sakwinska et al., 2011).

To date, molecular data on Staph. aureus from Swiss raw milk cheeses are largely lacking. The objective of this study was to characterize Staph. aureus isolates from Swiss raw milk cheeses contaminated with coagulase-positive staphylococci (CPS) and to estimate the frequency of the various genotypes, in particular the mastitis-associated Staph. aureus GTB. The isolates were also tested for SE genes and other virulence factors. Because methicillin-resistant Staph. aureus (MRSA) have been found in milk products and mastitis milk (Normanno et al., 2007; Huber et al., 2010) and because they are considered a major public health concern, we also screened our isolates for the presence of this resistance trait.

\section{MATERIALS AND METHODS}

\section{Bacterial Isolates from Raw Milk Cheeses}

In total, 623 isolates of CPS were analyzed. These strains (one or more per positive sample) were isolated from 78 bovine raw milk cheeses by different food control laboratories and were sent to our laboratory for further characterization. They originated from cheese curd $(\mathrm{n}=48)$ and finished cheese $(\mathrm{n}=30)$ produced in 60 dairies located throughout Switzerland.

With the exception of 5 soft cheeses, 1 fresh cheese, and 1 hard cheese, all samples were of semi-hard cheese type. For 63 samples, multiple (up to 10) isolates were available for testing.

\section{Bacteriological and Molecular Testing}

Upon arrival, all isolates were streaked on Baird Parker agar supplemented with rabbit plasma fibrinogen (BioMérieux, Marcy l'Etoile, France), blood agar (Oxoid, Basingstoke, UK) and Chromagar Staph. aureus (Chromagar, Paris, France). Subsequently, the CPS were screened by PCR for the presence of the nuc gene, which codes for thermonuclease and is specific for Staph. aureus (Brakstad et al., 1992). All Staph. aureus isolates (nuc-positive CPS with typical appearance on the different agars) were then subjected to genotyping (see below). Afterwards, 1 isolate of each genotype from each sample was further characterized. In case of multiple samples per cheese production site, each genotype was further characterized only once, even if it appeared several times.

Nucleic acid extraction; PCR amplification of nuc, coa, spa, tst, and lukE genes; and genotyping based on PCR amplification of the 16S-23S rRNA intergenic spacer region were performed as described by Fournier et al. (2008). The SE genes sea, seb, sec, sed, see, seg, seh, sei, sej, ser, and sep were amplified using 2 multiplex PCR protocols (De Buyser et al., 2009). In addition, all samples were further tested with singleplex PCR for sed, after Fournier et al. (2008), as weak 
sed amplification was occasionally observed with the multiplex reaction. All PCR products were analyzed by the miniaturized electrophoresis system DNA 7500 LabChip (Agilent Technologies, Basel, Switzerland). Furthermore, all CPS were screened for growth on MRSA brilliance agar (Oxoid) and tested by real-time PCR for the presence of the MRSA-specific mecA gene, after de Boer et al. (2009), using the Suremaster Probe V Mastermix with an internal amplification control (RBiopharm, Darmstadt, Germany) on a Rotorgene 6000 cycler (Corbett Research, Mortlake, Australia).

Staphylococcus aureus Protein A (spa) typing was performed by amplification of the spa gene followed by sequence analysis (Microsynth, Balgach, Switzerland) and assignment using the Ridom Staphtype software (Ridom GmbH, Würzburg, Germany; www.spaserver. ridom.de).

\section{SE Production Tests}

Isolates were grown aerobically on blood agar plates for 18 to $24 \mathrm{~h}$. A single colony was transferred into tryptic soy broth (Oxoid) and incubated aerobically at $37^{\circ} \mathrm{C}$ for 18 to $24 \mathrm{~h}$ under continuous shaking at 150 $\mathrm{rpm}$. Testing for enterotoxin production (SEA to SED) was done with the reversed passive latex agglutination assay (SET-RPLA; Oxoid) according to manufacturer's instructions.

\section{RESULTS}

In total, 609 of $623 \mathrm{CPS}$ isolates were found to be Staph. aureus (nuc-positive colonies with typical appearance on the media used). These Staph. aureus originated from 77 of the 78 raw milk cheese samples contaminated with CPS. Subsequent genotyping of all Staph. aureus isolates was performed by PCR amplification of the 16S-23S rRNA intergenic spacer region, as this method was used earlier to differentiate between mastitis subtypes associated with their clinical outcome (Fournier at al., 2008). The results for each sample are summarized in Table 1. The most frequently found genotypes were GTB with 386 (62.0\%), GTI with 72 (11.6\%), GTF with 54 (8.7\%), GTC with 25 (4.0\%), and GTA with $14(2.2 \%)$ among the isolated CPS. In addition to these genotypes, $15 \mathrm{OG}$ with low frequencies were found. The GTB isolates were abundant regardless of whether the isolates came from cheese curd or end products. At the sample level, the most frequently found genotypes - GTB, GTI, GTF, GTC, and GTAwere observed in 56 (71.8\%), 27 (35.6\%), 15 (19.2\%), 9 $(11.5 \%)$, and $5(6.4 \%)$ of the 78 samples, respectively (Table 2). However, in soft cheeses, the proportion of GTB was lower compared that that of GTI, whereas the opposite was observed for semi-hard cheeses. In addition, isolates belonging to GTB, GTI, GTF, GTC, and GTA were present in $41(68.3 \%), 20(33.3 \%), 12$ (20.0\%), 7 (11.6\%), and 5 (8.3\%) samples from the 60 different cheese production sites, respectively (data not shown). In 4 of 5 production facilities, where isolates from multiple samples were available and where GTB was present, this genotype persisted up to $27 \mathrm{wk}$ (at least 3 time points measured; data not shown). The most frequently occurring genotypes were observed in samples from all different regions of Switzerland (data not shown).

When several isolates per sample were available, up to 5 different genotypes could be detected (Table 1 ). The GTB isolate, when present in samples with multiple isolates, made up more than half of the isolates in 42 of $52(80.8 \%)$ cases; GTB was present in 14 of 21 of samples containing $>10^{5} \mathrm{cfu} / \mathrm{g}$ CPS.

The occurrence and distribution of virulence genes and their properties were studied in a subset of 107 isolates (Table 3). From 20 different genotypes, 14 represented isolates positive for $\mathrm{SE}$ genes and, from the most commonly found, only isolates of GTI carried no SE genes. Isolates of GTB and 4 OG contained at least one of the "classical" SE genes (sea to see). Neither seb nor see could be detected, and sea occurred exclusively in Staph. aureus GTB. In GTB isolates, the SE gene patterns sea, sed, sej, ser; sed, sej, ser; and sea were observed in $21(50.0 \%) ; 20(48.0 \%)$; and $1(2 \%)$ of the 42 cases. All but 2 isolates of OG being PCR-positive for SE genes contained one or more of the "new" SE genes, and in isolates representing 4 genotypes (GTC and $3 \mathrm{OG}$ ), the tst gene was present. The latter gene was always associated with the presence of sec or seg, sei. Several SE gene patterns were restricted to one distinct genotype each (all SE gene patterns in GTB; seh; sed, seg, sej, sep, ser; and sed, seg, sei in 3 different $\mathrm{OG}$ ), whereas others (seg, sei; sei) were found in more than one genotype. Between some of the isolates representing genotypes with the same SE gene pattern, differences were observed when additional tests on the luk and coa gene loci were applied (Table 3).

Sixty isolates carrying the classical SE genes were assessed in regard to their potential to produce enterotoxin in vitro. All strains produced SE, which was detected by the reversed passive latex agglutination test. However, in 6 GTB isolates with the sea, sed, sej, ser gene pattern, SEA production was not observed (Table 3).

Thirteen of $78(16.6 \%)$ cheese samples contaminated with CPS were free from isolates carrying SE, whereas 58 of $78(75.6 \%)$ contained isolates with the classical SE genes sea to see (mainly from GTB), and 7 contained isolates that contained exclusively new SE genes seg, seh, sei, sej, ser, and sep (data not shown). 


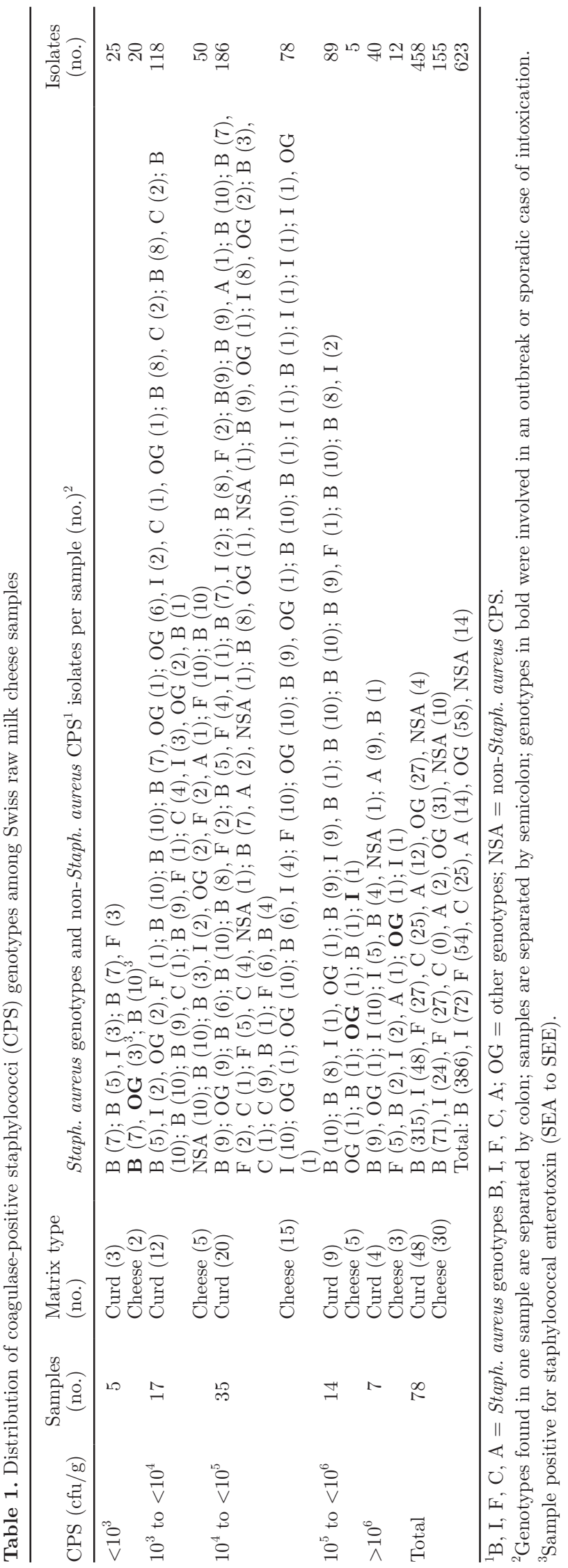

Additionally, we applied spa typing as a second subtyping scheme to our subset of Staph. aureus isolates (Table 3). The 20 different genotypes were split into 30 spa types. With the exception of spa types t1773 and t2094, which occurred in 2 different groups of genotypes, we found no overlap between spa types and genotypes found. The GTB isolate comprised 6 known spa types and 3 that have not been described before. However, t2953 clearly dominated within the isolates belonging to GTB, as it was present in 34 of 42 cases (81.0\%). Outside the GTB cluster, spa type t524 was predominant.

All 617 CPS isolates were screened by real-time PCR for the presence of the mecA gene, and 1 isolate was found to be positive. This isolate grew well on MRSA plates and was a Staph. aureus carrying the seh gene and belonging to spa type t127. The MRSA phenotype of this isolate was confirmed at the Institute for Infectious Diseases IFIK (University Hospital of Berne, Switzerland).

\section{DISCUSSION}

Our study of the enterotoxigenic properties and genotyping of Staph. aureus isolates from Swiss raw milk cheese revealed substantial diversity in the population of this pathogenic species. Up to 5 different genotypes were observed in an individual cheese, which is similar to the findings of a Norwegian study, where isolates with 6 different pulsed-field gel electrophoresis patterns were described in a particular cheese sample (Loncarevic et al., 2005). The same study found less diversity in raw milk, which can be explained by the fact that, for Staph. aureus, contamination sources other than raw milk exist. Potential sources are the production environment and food handlers. Most of the collected isolates in our study came from cheese curd in which the highest numbers of CPS are expected to occur during production. Therefore, samples taken at this stage of production are tested for whether the process complies with the requirements of the Ordinance of Hygiene (Federal Department of Home Affairs, 2014), which is identical to the European Commission (EC) regulation 2073/2005. In 22 of $61(36 \%)$ samples with multiple isolates of Staph. aureus, only 1 genotype was found. However, in an early processing step where curd is formed, up to 4 different genotypes were observed (in 2 samples; Table 1). In several cases, toxigenic and nontoxigenic isolates representing different genotypes were detected in the same samples. Therefore, we recommend testing multiple isolates from curd or cheese sampled in case of SFP outbreak investigations.

A diversity of 20 different genotypes has been identified in this study. However, only 5 genotypes oc- 
Table 2. Distribution of coagulase-positive staphylococci (CPS) genotypes among samples of different cheese types

\begin{tabular}{lccccccc}
\hline & \multicolumn{7}{c}{ Number (\%) } \\
\cline { 2 - 7 } Cheese type & $\mathrm{B}$ & $\mathrm{I}$ & $\mathrm{F}$ & $\mathrm{C}$ & $\mathrm{A}$ & OG & NSA \\
\hline Fresh $(\mathrm{n}=1)$ & 0 & 0 & 0 & 0 & 0 & 1 & 0 \\
Soft $(\mathrm{n}=5)$ & 2 & 5 & 1 & 0 & 1 & 1 & 0 \\
Semi-hard $(\mathrm{n}=71)$ & $53(74.7)$ & $22(31.0)$ & $14(19.7)$ & 9 & 3 & $24(33.8)$ & 5 \\
Hard $(\mathrm{n}=1)$ & 1 & 0 & 0 & 0 & 1 & 1 & 0 \\
Total $(\mathrm{n}=78)$ & $56(71.8)$ & $27(35.6)$ & $15(19.2)$ & 9 & 5 & $27(34.6)$ & 5 \\
\hline
\end{tabular}

${ }^{1}$ Staph. aureus genotypes B, I, F, C, A, and other genotypes (OG); NSA = non-Staph. aureus CPS.

curred in 6 to $72 \%$ of the samples, with GTB clearly dominating. Other studies also described high diversity but few dominating clusters of Staph. aureus isolates in milk or dairy products using different typing procedures such as random amplification of polymorphic DNA (RAPD)-PCR, pulsed-field gel electrophoresis, or amplified fragment length polymorphism (Villard et al., 2005; Boerema et al., 2006; Morandi et al., 2009). These authors showed associations between typing clusters and SE gene patterns in many but not all of the cases, a finding confirmed by our study.

We found 9 different SE gene patterns occurring in the subset of isolates, whereas $26 \%$ were SE gene negative (Table 3). The frequencies of SE gene negative isolates from dairy products vary remarkably between different reports; for example, $32 \%$ (Loncarevic et al., 2005) and 52\% (Rosec and Gigaud, 2002). In our study, SE gene patterns seg, sei; sea, sed, sej, ser; and sed, sej, ser dominated among our isolates, with 22, 20, and $19 \%$, respectively. At the single SE gene level, sed was most abundant (42\%). These findings are in contrast to studies from Japan, Austria, France, Norway, and Turkey, where sec was most commonly detected in milk and raw milk cheeses (Katsuda et al., 2005; Loncarevic et al., 2005; Villard et al., 2005; Gonano et al., 2009; Kav et al., 2011). However, several Italian studies reported a situation similar to our data with dominance of sed often associated with sea and sej (Cremonesi et al., 2007; Normanno et al., 2007; Morandi et al., 2009). These data possibly indicate a different prevalence of certain Staph. aureus subtypes in different geographical regions. In Switzerland, the SE genes sea and sed predominate because of the abundant occurrence of the mastitis-associated Staph. aureus GTB in Swiss dairy herds. Indeed, this subtype was found in $30 \%$ of milk samples submitted for diagnostic purposes (Fournier et al., 2008). Furthermore, this pathogen is contagious (Graber et al., 2009) so that, on average, half of the cows of a herd are infected (Fournier et al., 2008). These cows normally shed large amounts of this subtype $(>5$ $\times 10^{4} \mathrm{cfu} / \mathrm{mL}$ ) in the milk (Studer et al., 2008), leading to a high content of Staph. aureus GTB in the milk delivered to the dairy. As Swiss cheese-making facilities are normally small, using milk of only a limited number of different herds, it is not surprising that, under these circumstances, Staph. aureus GTB may become the predominant staphylococcal subtype in Swiss raw milk cheese, as found in the present study. This situation may become a food safety concern if the Staph. aureus GTB bacteria further grow in the processed milk because of inappropriate milk storage and hygiene. Under these conditions, they may produce SE (Hennekinne et al., 2012), which may lead to food intoxication, as was observed in the present study (Table 1).

Our data on the presence of SE, including the association with SFP, show that Staph. aureus belonging to GTB, among other genotypes, can be the source of intoxication followed by illness (Table 1). In one case, the incriminated cheese originated from a production site where Staph. aureus GTB was widespread in the associated milk-producing herd. The majority of isolates from this sample belonged to GTB/t2953, carrying sea and sed, and therefore had the potential to produce SEA and SED in vitro. Furthermore, the incriminated cheese was reported to be positive for $\mathrm{SE}$ (A to E). A second cheese sample, from which only GTB/t2953 could be isolated, was found to be SE positive (A to $\mathrm{E}$ ), but no SFP was reported in this case. In another report, Staph. aureus t2953 was described as the causative agent in an SFP outbreak due to contaminated milk (Schmid et al., 2009). Whether the abundant occurrence of GTB/t2953 in CPS-positive Swiss cheeses leads to an increased number of SFP remains to be elucidated and is complicated by the fact that SFP is known to be underreported. This could be especially true for Switzerland with its large number of small production facilities. In addition, our results show that GTB strains do not always produce SEA protein in vitro. Whether the potential of Staph. aureus GTB to cause SFP is reduced in such cases has to be examined in further studies.

In addition to its problematic role in food safety, Staph. aureus GTB causes high costs in Swiss dairy herds because antibiotic treatment of cows with mas- 
Table 3. Distribution of virulence genes and their properties, enterotoxin production, methicillin resistance, and spa types among Staph. aureus genotypes B, I, F, C, A, and other genotypes $(\mathrm{OG})$

\begin{tabular}{|c|c|c|c|c|c|c|c|c|c|}
\hline \multirow{2}{*}{$\begin{array}{l}\text { Genotype, } \\
\text { isolates (no.) }\end{array}$} & \multicolumn{9}{|c|}{ Isolates positive for a particular gene, enterotoxin production, polymorphism, or spa type ${ }^{1}$ (n) } \\
\hline & Toxin gene pattern & SET RPLA & lukE & $\operatorname{lukEB}$ & $l u k E C$ & spa & coa & mecA & spa type \\
\hline \multirow[t]{3}{*}{ B (42) } & sea, sed, sej, ser (21) & A, D (16); D (5) & $+(21)$ & $+(21)$ & $-(21)$ & $+(21)$ & $+(21)$ & $-(21)$ & \multirow{2}{*}{$\begin{array}{l}\text { t2953 (15), t5268 (2), t334 (1), t3802 (1) } \\
\text { t5271 (1), unknown (1) } \\
\text { t2953 (19), t5268 (1) }\end{array}$} \\
\hline & sed, sej, ser $(20)$ & $\mathrm{D}(20)$ & $+(20)$ & $+(20)$ & $-(20)$ & $+(20)$ & $+(20)$ & $-(20)$ & \\
\hline & sea $(1)$ & $\mathrm{A}(1)$ & $+(1)$ & $+(1)$ & $-(1)$ & $+(1)$ & $+(1)$ & $-(1)$ & unknown (1) \\
\hline I (20) & $-(20)$ & $\mathrm{NA}$ & $+(20)$ & $+(20)$ & $-(20)$ & $+(20)$ & $-(20)$ & $-(20)$ & t524 (20) \\
\hline $\mathrm{F}(13)$ & seg, sei (13) & NA & $+(13)$ & $-(13)$ & $+(13)$ & $+(13)$ & $+(13)$ & $-(13)$ & $\begin{array}{l}\mathrm{t} 164(8), \mathrm{t} 2094(2), \mathrm{t} 1987(1), \\
\mathrm{t} 2736(1), \text { unknown (1) }\end{array}$ \\
\hline \multirow[t]{2}{*}{$\mathrm{C}(7)$} & seg, sei $(6)$, tst $(1)$ & NA & $+(6)$ & $-(6)$ & $+(6)$ & $+(6)$ & $+(6)$ & $-(6)$ & $\mathrm{t} 529(6)$ \\
\hline & $\operatorname{sei}(1)$ & NA & $+(1)$ & $-(1)$ & $+(1)$ & $+(1)$ & $+(1)$ & $-(1)$ & unknown (1) \\
\hline \multirow[t]{2}{*}{$\mathrm{A}(5)$} & $\operatorname{seh}(4)$ & NA & $+(4)$ & $+(4)$ & $-(4)$ & $+(4)$ & $+(4)$ & $-(4)$ & $\mathrm{t} 127(3), \mathrm{t} 2207(1)$ \\
\hline & $\operatorname{seh}(1)$ & $\mathrm{NA}$ & $+(1)$ & $+(1)$ & $-(1)$ & $+(1)$ & $+(1)$ & $+(1)$ & $\mathrm{t} 127(1)$ \\
\hline \multirow[t]{6}{*}{$\mathrm{OG}^{2}(20)$} & $-(8)^{3}$ & NA & $+(8)$ & Var. & $-(8)$ & $-(8)$ & $-(8)$ & $-(8)$ & $\begin{array}{l}\mathrm{t} 4201(1), \mathrm{t} 5428(1), \mathrm{t} 156(1), \mathrm{t} 3904(3), \\
\mathrm{t} 1773(1), \mathrm{t} 2678(1)\end{array}$ \\
\hline & seg, sei (4) & $\begin{array}{l}\mathrm{NA} \\
\mathrm{C}(2)\end{array}$ & Var. & Var. & Var. & Var. & Var. & $-(4)$ & t330 (1), t1544 (1), t015 (1), t2094 (1) \\
\hline & sed, seq, sei, sej, sep, ser (2) & $\mathrm{D}(2)$ & $\begin{array}{l}+(2) \\
+(2)\end{array}$ & $\begin{array}{l}\text { var. } \\
+(2)\end{array}$ & $\begin{aligned} v a r \\
-(2)\end{aligned}$ & $+(2)$ & $\begin{array}{l}-(2) \\
-(2)\end{array}$ & $\begin{array}{l}-(2) \\
-(2)\end{array}$ & $\begin{array}{l}\text { t544(1), t1673(1) } \\
\text { t442(2) }\end{array}$ \\
\hline & sed, seg, sei (2) & $\mathrm{D}(2)$ & $+(2)$ & $-(2)$ & $+(2)$ & $+(2)$ & $+(2)$ & $-(2)$ & t7013 (2) \\
\hline & $\operatorname{sei}(1)$ & $\mathrm{NA}$ & $-(1)$ & $+(1)$ & $-(1)$ & $+(1)$ & $+(1)$ & $-(1)$ & $\mathrm{t} 246(1)$ \\
\hline & seg, sei, tst (1) & NA & $-(1)$ & $-(1)$ & $-(1)$ & $+(1)$ & $-(1)$ & $-(1)$ & t021 (1) \\
\hline
\end{tabular}

${ }_{1}^{1}$ sea, sec, sed, seg, seh, sei, sej, ser, sep, tst = staphylococcal enterotoxin genes and toxic shock syndrome toxin-1 gene; SET RPLA = in vitro production of staphylococcal enterotoxins A to D detected by reversed passive latex agglutination assay; lukE, lukEB, lukEC = polymorphisms of different leukocidin gene components; spa = gene of protein A (amplicon size $\geq 250 \mathrm{bp}$ ); coa = coagulase gene (amplicon size $640 \mathrm{bp}$ ); mecA = presence of methicillin resistance gene (MRSA); spa type $=$ spa type according to Ridom database; $\mathrm{NA}=$ not assessed; Var. = variable result.

${ }^{2}$ Other sporadically appearing genotypes (15) were summarized as OG.

${ }^{3}$ Isolates being PCR-negative for SE genes came from 5 different OG. 
titis caused by Staph. aureus is inefficient (Gruet et al., 2001) and most such cows need to be slaughtered. It would be highly desirable, therefore, to minimize Staph. aureus GTB at the country level, although this would require a suitable diagnostic assay. Such a test was recently developed by Boss et al. (2011) and was evaluated in a field study (Syring et al., 2012). It is based on real-time quantitative PCR and is highly sensitive and specific for Staph. aureus GTB such that bulk tank milk may be tested, which greatly simplifies the sampling logistics.

We applied spa typing to a subset of our Staph. aureus isolates, as this scheme has been used successfully in both clinical and food microbiology investigations (Koreen et al., 2004; de Boer et al., 2009; Hata et al., 2010). The spa typing revealed that the majority of Staph. aureus GTB belonged to spa type t2953 (Table 2 ). This type, and the other frequently appearing spa types from our study [t529 (GTC); t164, t2094, t1987 (GTF); t524 (GTI)], have been well described in bovine isolates from different countries worldwide (Ikawaty et al., 2009; Hasman et al., 2010; Hata et al., 2010; Hwang et al., 2010; Johler et al., 2011; Sakwinska et al., 2011).

Other spa types grouped into clonal complexes known from studies in humans; for example, t127 and t015. This indicates that several isolates from this study seemed to be of human origin. Among these, one isolate was found to be a MRSA and this is, to our knowledge, the first MRSA isolated from a ready-to-eat food item in Switzerland. The MRSA prevalence within isolates reported here was very low $(0.002 \%)$, but it is in concordance with another Swiss study (Huber et al., 2010) and in contrast to reports on MRSA in meat $(12 \%)$ or cheese $(7 \%)$ from other countries (de Boer et al., 2009; Kav et al., 2011).

\section{CONCLUSIONS}

Several subtypes (genotypes and spa types) of Staph. aureus with different pathogenic and epidemiological properties can be found in Swiss raw milk cheese. Of these subtypes, strains of the mastitis-associated Staph. aureus GTB were most frequently found in cheeses contaminated with coagulase-positive staphylococci. Because these strains carry the SE genes sea, sed, sej, ser or sed, sej, ser, they can be linked to toxin production in cheese and food poisoning outbreaks. Therefore, control and reduction of Staph. aureus GTB in dairy herds will not only prevent economic losses at the farm level but also improve safety of raw milk cheeses. The distribution of MRSA via Swiss raw milk cheese is of less concern.

\section{ACKNOWLEDGMENTS}

B. Felix and B. Lombard (European Union Reference Laboratory for coagulase positive Staphylococci, ANSES, Maisons-Alfort, France) are acknowledged for providing reference strains and reference method for SE gene detection. The Swiss Cantonal Laboratories are thanked for providing isolates from the national surveillance program on milk and milk products (Coordinator: E. Breidenbach, Swiss Federal Veterinary Office, Berne). We thank M. Täuber and the late K. Mühlemann (Institute for Infectious Diseases IFIK, University Hospital of Berne) for the confirmation of the MRSA isolate. T. Berger (Agroscope LiebefeldPosieux ALP, Berne, Switzerland) is acknowledged for critical reading of the manuscript.

\section{REFERENCES}

Balaban, N., and A. Rasooly. 2000. Staphylococcal enterotoxins. Int. J. Food Microbiol. 61:1-10.

Baumgartner, A. 2008. Outbreaks with microbial contaminated foodstuffs in Switzerland 1994-2006. Bull. Swiss Federal Off. Public Health 32:562-568.

Boerema, J. A., R. Clemens, and G. Brightwell. 2006. Evaluation of molecular methods to determine enterotoxigenic status and molecular genotype of bovine, ovine, human and food isolates of Staphylococcus aureus. Int. J. Food Microbiol. 107:192-201.

Boss, R., J. Naskova, A. Steiner, and H. U. Graber. 2011. Mastitis diagnostics: Quantitative PCR for Staphylococcus aureus genotype B in bulk tank milk. J. Dairy Sci. 94:128-137.

Brakstad, O. G., K. Aasbakk, and J. A. Maeland. 1992. Detection of Staphylococcus aureus by polymerase chain reaction amplification of the nuc gene. J. Clin. Microbiol. 30:1654-1660.

Cremonesi, P., G. Perez, G. Pisoni, P. Moroni, S. Morandi, M. Luzzana, M. Brasca, and B. Castiglioni. 2007. Detection of enterotoxigenic Staphylococcus aureus isolates in raw milk cheese. Lett. Appl. Microbiol. 45:586-591.

de Boer, E., J. T. Zwartkruis-Nahuis, B. Wit, X. W. Huijsdens, A. J. de Neeling, T. Bosch, R. A. van Oosterom, A. Vila, and A. E. Heuvelink. 2009. Prevalence of methicillin-resistant Staphylococcus aureus in meat. Int. J. Food Microbiol. 134:52-56.

De Buyser, M. L., B. Dufour, M. Maire, and V. Lafarge. 2001. Implication of milk and milk products in food-borne diseases in France and in different industrialised countries. Int. J. Food Microbiol. $67: 1-17$.

De Buyser, M. L., J. Grout, A. Brisabois, A. Assere, and B. Lombard. 2009. Detection of genes encoding staphylococcal enterotoxins. Multiplex PCR for sea to see and ser. Multiplex PCR for seg to sej and sep. Methods of the European Community Reference Laboratory for coagulase positive staphylococci, including Staphylococcus aureus. European Community Reference Laboratory, MaisonsAlfort, France.

Derzelle, S., F. Dilasser, M. Duquenne, and V. Deperrois. 2009. Differential temporal expression of the staphylococcal enterotoxins genes during cell growth. Food Microbiol. 26:896-904.

Duquenne, M., I. Fleurot, M. Aigle, C. Darrigo, E. Borezée-Durant, S. Derzelle, M. Bouix, V. Deperrois-Lafarge, and A. DelacroixBuchet. 2010. Tool for quantification of staphylococcal enterotoxin gene expression in cheese. Appl. Environ. Microbiol. 76:13671374 .

Federal Department of Home Affairs. 2014. Ordinance on Hygiene from November 23, 2005; Version from January 1, 2014. SR 817.024.1. 
Accessed Jan. 6, 2014. http://www.admin.ch/opc/de/classifiedcompilation/20050160/index.html.

Fournier, C., P. Kuhnert, J. Frey, R. Miserez, M. Kirchhofer, T. Kaufmann, A. Steiner, and H. U. Graber. 2008. Bovine Staphylococcus aureus: Association of virulence genes, genotypes and clinical outcome. Res. Vet. Sci. 85:439-448.

Gonano, M., I. Hein, P. Zangerl, A. Rammelmayr, and M. Wagner. 2009. Phenotypic and molecular characterization of Staphylococcus aureus strains of veterinary, dairy and human origin. Epidemiol. Infect. 137:688-699.

Graber, H. U., J. Naskova, E. Studer, T. Kaufmann, M. Kirchhofer, M. Brechbühl, W. Schaeren, A. Steiner, and C. Fournier. 2009. Mastitis-related subtypes of bovine Staphylococcus aureus are characterized by different clinical properties. J. Dairy Sci. 92:1442-1451.

Gruet, P., P. Maincent, X. Berthelot, and V. Kaltsatos. 2001. Bovine mastitis and intramammary drug delivery: Review and perspectives. Adv. Drug Deliv. Rev. 50:245-259.

Hasman, H., A. Moodley, L. Guardabassi, M. Stegger, R. L. Skov, and F. M. Aarestrup. 2010. Spa type distribution in Staphylococcus aureus originating from pigs, cattle and poultry. Vet. Microbiol. 141:326-331

Hata, E., K. Katsuda, H. Kobayashi, I. Uchida, K. Tanaka, and M. Eguchi. 2010. Genetic variation among Staphylococcus aureus strains from bovine milk and their relevance to methicillin-resistant isolates from humans. J. Clin. Microbiol. 48:2130-2139.

Hennekinne, J. A., M. L. De Buyser, and S. Dragacci. 2012. Staphylococcus aureus and its food poisoning toxins: Characterization and outbreak investigation. FEMS Microbiol. Rev. 36:815-836.

Huber, H., S. Koller, N. Giezendanner, R. Stephan, and C. Zweifel. 2010. Prevalence and characteristics of methicillin-resistant Staphylococcus aureus in humans in contact with farm animals, in livestock, and in food of animal origin, Switzerland, 2009. Euro Surveill. 15:19542.

Hwang, S. Y., Y. K. Park, H. C. Koo, and Y. H. Park. 2010. Spa typing and enterotoxin gene profile of Staphylococcus aureus isolated from bovine raw milk in Korea. J. Vet. Sci. 11:125-131.

IDF. 2005. Economic consequences of mastitis. Bull. Int. Dairy Fed. No. 394. Int. Dairy Fed., Brussels, Belgium.

Ikawaty, R., E. C. Brouwer, M. D. Jansen, E. van Duijkeren, D. Mevius, J. Verhoef, and A. C. Fluit. 2009. Characterization of Dutch Staphylococcus aureus from bovine mastitis using a Multiple Locus Variable Number Tandem Repeat Analysis. Vet. Microbiol. 136:277-284

Johler, S., F. Layer, and R. Stephan. 2011. Comparison of virulence and antibiotic resistance genes of food poisoning outbreak isolates of Staphylococcus aureus with isolates obtained from bovine mastitis milk and pig carcasses. J. Food Prot. 74:1852-1859.

Jørgensen, H. J., T. Mørk, and L. M. Rørvik. 2005. The occurrence of Staphylococcus aureus on a farm with small-scale production of raw milk cheese. J. Dairy Sci. 88:3810-3817.

Katsuda, K., E. Hata, H. Kobayashi, M. Kohmoto, K. Kawashima, H. Tsunemitsu, and M. Eguchi. 2005. Molecular typing of Staphylococcus aureus isolated from bovine mastitic milk on the basis of toxin genes and coagulase gene polymorphisms. Vet. Microbiol. 105:301-305.
Kav, K., R. Col, and M. Ardic. 2011. Characterization of Staphylococcus aureus isolates from white-brined Urfa cheese. J. Food Prot. 74:1788-1796.

Kérouanton, A., J. A. Hennekinne, C. Letertre, L. Petit, O. Chesneau, A. Brisabois, and M. L. De Buyser. 2007. Characterization of Staphylococcus aureus strains associated with food poisoning outbreaks in France. Int. J. Food Microbiol. 115:369-375.

Koreen, L., S. V. Ramaswamy, E. A. Graviss, S. Naidich, J. M. Musser, and B. N. Kreiswirth. 2004. spa typing method for discriminating among Staphylococcus aureus isolates: Implications for use of a single marker to detect genetic micro- and macrovariation. J. Clin. Microbiol. 42:792-799.

Loncarevic, S., H. J. Jørgensen, A. Løvseth, T. Mathisen, and L. M. Rørvik. 2005. Diversity of Staphylococcus aureus enterotoxin types within single samples of raw milk and raw milk products. J. Appl. Microbiol. 98:344-350.

Morandi, S., M. Brasca, C. Andrighetto, A. Lombardi, and R. Lodi 2009. Phenotypic and genotypic characterization of Staphylococcus aureus strains from Italian dairy products. Int. J. Microbiol. 2009:501362. http://dx.doi.org/10.1155/2009/501362.

Normanno, G., M. Corrente, G. La Salandra, A. Dambrosio, N. C. Quaglia, A. Parisi, G. Greco, A. L. Bellacicco, S. Virgilio, and G. V. Celano. 2007. Methicillin-resistant Staphylococcus aureus (MRSA) in foods of animal origin product in Italy. Int. J. Food Microbiol. 117:219-222.

Pexara, A., N. Solomakos, D. Sergelidis, and A. Govaris. 2012. Fate of enterotoxigenic Staphylococcus aureus and staphylococcal enterotoxins in Feta and Galotyri cheeses. J. Dairy Res. 79:405-413.

Rosec, J. P. and O. Gigaud. 2002. Staphylococcal enterotoxin genes of classical and new types detected by PCR in France. Int. J. Food Microbiol. 77:61-70.

Sakwinska, O., M. Giddey, M. Moreillon, D. Morisset, A. Waldvogel, and P. Moreillon. 2011. Staphylococcus aureus host range and human-bovine host shift. Appl. Environ. Microbiol. 77:5908-5915.

Schmid, D., R. Fretz, P. Winter, M. Mann, G. Höger, A. Stöger, W Ruppitsch, J. Ladstätter, N. Mayer, A. de Martin, and F. Allerberger. 2009. Outbreak of staphylococcal food intoxication after consumption of pasteurized milk products, June 2007, Austria. Wien. Klin. Wochenschr. 121:125-131.

Studer, E., W. Schaeren, J. Naskova, H. Pfaeffli, T. Kaufmann, M. Kirchhofer, A. Steiner, and H. U. Graber. 2008. A longitudinal field study to evaluate the diagnostic properties of a quantitative real-time polymerase chain reaction-based assay to detect Staphylococcus aureus in milk. J. Dairy Sci. 91:1893-1902.

Syring, C., R. Boss, M. Reist, M. Bodmer, J. Hummerjohann, P. Gehrig, and H. U. Graber. 2012. Bovine mastitis: The diagnostic properties of a PCR-based assay to monitor the Staphylococcus aureus genotype B status of a herd, using bulk tank milk. J. Dairy Sci. 95:3674-3682.

Villard, L., H. Lamprell, E. Borges, F. Maurin, Y. Noel, E. Beuvier, J. F. Chamba, and A. Kodjo. 2005. Enterotoxin D producing strains of Staphylococcus aureus are typeable by pulsed-field gel electrophoresis (PFGE). Food Microbiol. 22:261-265. 